\title{
Morningness- Eveningness Preferences among First Year Medical Students
} Dr. Arifuddin $\mathrm{MK}^{1}$, Dr. Shashiraj $\mathrm{HK}^{2 *}$, Dr. Kavitha BS ${ }^{1}$

${ }^{1}$ Assistant Professor, Department of Physiology, Sri Siddhartha Medical College, Tumkur, India

${ }^{2}$ Associate Professor, Department of Physiology, Sri Siddhartha Medical College, Tumkur, India

*Corresponding author: Dr. Shashiraj HK

\section{Abstract}

Background: Morningness and eveningness is a phenomenon which looks at the differences among individuals regarding their diurnal preferences, sleep-wake pattern of activity, and alertness in evening or morning. Morning chronotypes are known to exhibit better physical and mental health, greater self esteem and academic performance. Evening chronotypes has been to be associated with several mental disorders, infection prone and have poor sleep quality. Students of Medicine have an average of sleep duration of $6 \mathrm{hrs}$ per day in contrast to $8 \mathrm{hrs}$ of sleep which is seen in other groups. Objectives: To study the morningness eveningness preferences among first year medical students. Methodology: With the approval of Institutional ethical committee this cross sectional study was carried out among 130 first year medical students. Informed consent was taken and the British version of the Horne and Ostberg questionnaire was administered. Confidentiality was maintained and the recorded responses were analyzed using Microsoft excel and Epi Info 7. Results: $34.61 \%$ (45) of the study population belong to moderate evening category and 13.07\% (17) to definite evening category. Ours study also reveals that $9.23 \%$ (12) belong to neither of the morning or evening categories. Our results also show that $26.15 \%$ (34) belong to definite morning types and $16.92 \%$ (22) belong to moderate morning types. Conclusion: Our study shows that the study population which is first year MBBS students show more inclination towards eveningness. Scheduling of academic activities based on the chronotypes will help the students to improve upon their academic performance.

Keywords: Morningness, Eveningness, sleep-wake pattern, mental health, academic performance, chronotypes.

Copyright $\odot 2021$ The Author(s): This is an open-access article distributed under the terms of the Creative Commons Attribution 4.0 International License (CC BY-NC 4.0) which permits unrestricted use, distribution, and reproduction in any medium for non-commercial use provided the original author and source are credited.

\section{INTRODUCTION}

Physiological body functions is said to vary throughout the day due to the circadian rhythm which looks at human activities recorded during 24 hour sleep-wake cycle. Cognitive performance is substantially influence by the expression of normal sleep and wakefulness [1].

In the last decade various factors such as use of internet and social media platforms by mobile phones as led to altered sleep pattern and excessive daytime sleepiness [2].

Studies conducted earlier has shown the relationship between the quality of sleep and academic performance. There is also evidence that there is higher prevalence of sleep problems among college students [3].
Students of Medicine have an average of sleep duration of $6 \mathrm{hrs}$ per day in contrast to $8 \mathrm{hrs}$ of sleep which is seen in other groups [4].

Morningness and eveningness is a phenomenon which looks at the differences among individuals regarding their diurnal preferences, sleepwake pattern of activity, and alertness in evening or morning. Morning chronotypes are individuals who exhibit morning tendencies like raising early in the morning and also who are at their best both physically and mentally in the early hours of morning [5].

Evening chronotypes are individuals who prefer to get up latter in the morning and stay awake latter at night time and also perform their best during late afternoons or evenings [5].

Diurnal preferences show association to various issues such as eating behavior, sleep pattern and usage of recreational drugs [5]. 
Arifuddin MK et al; Sch Int J Anat Physiol, Mar., 2021; 4(3): 32-34

Morning chronotypes are known to exhibit better physical and mental health, greater self esteem and academic performance. Evening chronotypes has been to be associated with several mental disorders, infection prone and have poor sleep quality [6].

Academic pressure, vastness of the curriculum and issues related stress are some of the factors which lead to misalign synchronization irrespective of their chronotype $[7,8]$.

Hence the present study was conducted to assess morningness and eveningness among first year medical students of 2015- 16 batch at Sri Siddhartha Medical College, Tumkur, Karnataka.

Objectives: To study the morningness eveningness preferences among first year medical students.

\section{MATERIAL AND METHODS}

With the approval of Institutional ethical committee this cross sectional study was carried out among 130 first year medical students of 2015-16 batch belonging to Sri Siddhartha Medical College, Tumkur, Karnataka. Informed consent was taken and the British version of the Horne and Ostberg questionnaire was administered to the study population. The questionnaire scoring system awards $0-6$ points for the answer to each question with lowest possible score being 16 and the highest 86. Confidentiality was maintained and the recorded responses were analyzed using Microsoft excel and Epi Info 7.

\section{RESULTS}

Table-1: Age and gender distribution

\begin{tabular}{|l|l|l|}
\hline & Mean & Standard deviation \\
\hline $\begin{array}{l}\text { Age of the } \\
\text { subject }\end{array}$ & 18.07 & 0.62 \\
\hline Sex & Frequency & Percentage \\
\hline Female & 60 & 46.20 \\
\hline Male & 70 & 53.80 \\
\hline
\end{tabular}

Table-2: Individual chronotypes

\begin{tabular}{|l|l|l|}
\hline Preference type & Frequency & Percentage \\
\hline Definite morning & 34 & 26.15 \\
\hline Moderate morning & 22 & 16.92 \\
\hline Neither & 12 & 9.23 \\
\hline Moderate evening & 45 & 34.61 \\
\hline Definite evening & 17 & 13.07 \\
\hline \multicolumn{3}{|c|}{ Definite morning - 70 -86 } \\
Moderate morning - 59-69 \\
Neither - 42-58 \\
Moderate evening - 31-41 \\
Definite evening - 16-30
\end{tabular}

\section{DISCUSSION}

Light dark alteration which is one of the strongest external circadian "Zeitgeber" for human beings. Modern day lifestyle has led to transformation of people moving towards eveningness because of technological preferences. Eveningness is known to affect human beings physically and also has detrimental effect on mental health [9].

In a study done by Fabbial F. as shown that eveningness as an impact on academic achievement [9].

Horne and Ostberg questionnaire which is used to assess morningness and eveningness as been validated in many other studies [10-12]. The questionnaire defines the individual chronotypes based on this scoring - Definite morning - 70 -86, Moderate morning - 59-69, Neither - 42-58, Moderate evening 31-41, Definite evening - 16-30.

The results as shown in Table-2 shows more inclination of the study population towards eveningness wherein $34.61 \%$ (45) belong to moderate evening category and $13.07 \%$ (17) belong to definite evening category. Ours study also reveals that $9.23 \%$ (12) belong to neither of the morning or evening categories. Our results also show that $26.15 \%$ (34) belong to definite morning types and $16.92 \%$ (22) belong to moderate morning types.

Our study findings are consistent with another study done by Mark T. Steele who has looked at the morningness and eveningness preferences among emergency medicine residents at a medical centre at Kansas city [13].

Our study which shows that the students are more likely to belong to eveningness chronotypes which is similar to another study done by Rique GL in medical students from Brazil in which he also concluded that inclination towards eveningness can potentially impair academic performance [4].

\section{CONCLUSION}

Our study shows that the study population which is first year MBBS students show more inclination towards eveningness. Scheduling of academic activities based on the chronotypes will help the students to improve upon their academic performance. It is suggested that proper scheduling of curricular and academic activities to fit the circadian clock of the students.

\section{RECOMMENDATIONS}

There is a need for assessment of factors that influence the morningness and eveningness among medical students. 
Arifuddin MK et al; Sch Int J Anat Physiol, Mar., 2021; 4(3): 32-34

\section{REFERENCES}

1. Mirghani, H. O., Mohammed, O. S., Almurtadha, Y. M., \& Ahmed, M. S. (2015). Good sleep quality is associated with better academic performance among Sudanese medical students. BMC research notes, 8(1), 1-5.

2. Pagel, J. F. (2009). Excessive daytime sleepiness. American family physician, 79(5), 391396.

3. Jabeen, S., Matloob, A., \& Mirza, N. (2015). Academic accomplishment; influence of diurnal preference in medical students. Prof Med J. 2015;22(8):1087-1090.

4. Rique, G. L. N., Fernandes Filho, G. M. C., Ferreira, A. D. C., \& de Sousa-Munoz, R. L. (2014). Relationship between chronotype and quality of sleep in medical students at the Federal University of Paraiba, Brazil. Sleep Science, 7(2), 96-102.

5. Urbán, R., Magyaródi, T., \& Rigó, A. (2011). Morningness-eveningness, chronotypes and health-impairing behaviors in adolescents. Chronobiology international, 28(3), 238-247.

6. Concepcion, T., Barbosa, C., Vélez, J. C., Pepper, M., Andrade, A., Gelaye, B., ... \& Williams, M. A. (2014). Daytime sleepiness, poor sleep quality, eveningness chronotype, and common mental disorders among Chilean college students. Journal of American College Health, 62(7), 441-448.
7. Cardoso, H. C., Bueno, F. C. D. C., Mata, J. C. D., Alves, A. P. R., Jochims, I., Vaz Filho, I. H. R., \& Hanna, M. M. (2009). Avaliação da qualidade do sono em estudantes de Medicina. Revista Brasileira de Educação Médica, 33(3), 349-355.

8. Valentinuzzi, V. S., \& Fontenele Araujo, J. (2008). Los ritmos biológicos y le aprendizaje. Ingenierías, 11(40), 41-46.

9. Fabbian, F., Zucchi, B., De Giorgi, A., Tiseo, R., Boari, B., Salmi, R., ... \& Manfredini, R. (2016). Chronotype, gender and general health. Chronobiology international,33(7), 863882.

10. Motohashi, Y. (1988). Sex differences in the momingness-eveningness preferences in student and hospital nurse samples. Ind Health. 26:245249.

11. Horne, J. A., \& Östberg, O. (1976). A selfassessment questionnaire to determine morningness-eveningness in human circadian rhythms. International journal of chronobiology, 4:97-110.

12. Mecacci, L., \& Zani, A. (1983). Morningnesseveningness preferences and sleep-waking diary data of morning and evening types in student and worker samples. Ergonomics, 26(12), 1147-1153.

13. Steele, M. T., McNamara, R. M., Smith- Coggins, R., \& Watson, W. A. (1997). Morningnesseveningness preferences of emergency medicine residents are skewed toward eveningness. Academic emergency medicine, 4(7), 699-705. 